Revista de la red interuniversitaria de estudios sobre las literaturas rioplatenses contemporáneas en Francia

19 | 2018

La rebelión de los hijos: el judaísmo en la literatura latinoamericana contemporánea entre tradición y asimilación

\title{
La negatividad intransigente de Saer
}

\section{Perrine Guéguen}

\section{(2) OpenEdition}

\section{Journals}

Edición electrónica

URL: http://journals.openedition.org/lirico/6776

DOI: $10.4000 /$ lirico.6776

ISSN: 2262-8339

Editor

Réseau interuniversitaire d'étude des littératures contemporaines du Río de la Plata

Referencia electrónica

Perrine Guéguen, «La negatividad intransigente de Saer », Cuadernos LIRICO [En línea], 19 | 2018,

Publicado el 12 diciembre 2018, consultado el 24 septiembre 2020. URL : http://

journals.openedition.org/lirico/6776; DOI : https://doi.org/10.4000/lirico.6776

Este documento fue generado automáticamente el 24 septiembre 2020

\section{cc)}

Cuadernos LIRICO está distribuido bajo una Licencia Creative Commons Atribución-NoComercial-

SinDerivar 4.0 Internacional. 


\title{
La negatividad intransigente de
} Saer

\author{
Perrine Guéguen
}

REFERENCIA

Lucero, Nicolás. La vuelta incompleta. Saer y la novela. Buenos Aires, Santiago Arcos Editor, 2017, 290 páginas 
El título del libro recién publicado La vuelta incompleta ${ }^{1}$ de Nicolás Lucero alude a la novela de Juan José Saer, La vuelta completa, destacando la incomplétude como marca fuerte del estilo de la prosa saeriana. Saer consideraba que la novela se había agotado con Bouvard y Pécuchet y subrayaba la necesidad de renovar la narración. Lucero propone volver a problematizar su escritura a partir de la negatividad, apoyándose en su producción ensayística. Así, el estudio de Lucero abarca la negatividad de lo inefable, de lo inacabado y del mito del escritor fallido, que se constituyen como ejes de exploración de la experimentación formal saeriana.

2 En este sentido, el crítico explora los

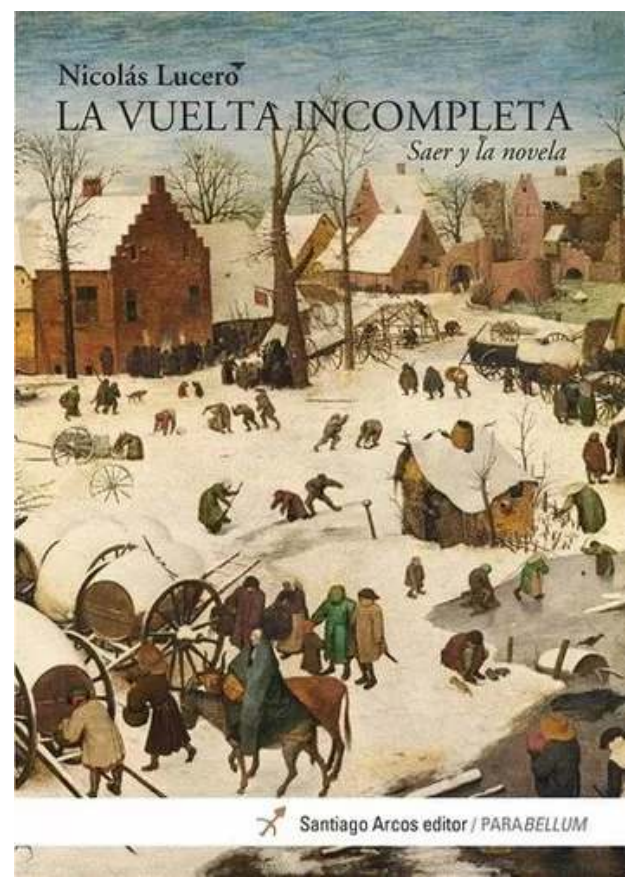
contrapuntos y las zonas de contacto entre varias novelas, basándose en un corpus que abarca sobre todo los periodos de formación y de experimentación del escritor, entre tanteos formales y búsquedas técnicas. En su análisis destaca los procedimientos de escritura de varias novelas: En la zona (1960), Responso (1964), La vuelta completa (1966), Cicatrices (1969), El limonero real (1974), Nadie nada nunca (1980) y Glosa (1986) principalmente. No obstante, no se trata de un mero recorrido cronológico, sino más bien de un análisis y una lectura en permanente diálogo con la crítica saeriana hoy "clásica" -María Teresa Gramuglio, Beatriz Sarlo, Julio Premat entre otros- y con la producción ensayística de Juan José Saer, sobre todo El río sin orillas (1991) y El concepto de ficción (1997). También abundan referencias menos esperadas como Edward Said, Georges Poulet o Bertolt Brecht. Sobre todo, vuelve a pensar la dinámica de la obra y del pensamiento de Saer al examinar la obra bajo el prisma del pensamiento de Theodor Adorno. Así, el concepto de incomplétude, que aparece desde el título del libro, es una referencia a la negatividad estética de corte adorniano que sostiene la exploración formal constante en Saer. La dialéctica negativa es vista entonces como el eje principal de su pensamiento estético: actúa como bisagra entre la producción ensayística, la obra en prosa, el programa literario y la constante polémica con otras estéticas.

Por otra parte, si bien la reflexión de Lucero se origina en el pensamiento adorniano, la idea que estructura el libro es la necesidad de volver a pensar las claves topológicas de la obra de Juan José Saer. En esta perspectiva, Lucero enmarca su análisis en la crítica de Mijaíl Batjín, insistiendo en su concepto de "extraposición" -o sea el movimiento gracias al cual el autor se distancia del personaje y que se caracteriza por una relación de "exotopía"-. La estructura del libro deriva de esos conceptos narratológicos y se declina a través de cuatro capítulos: 1 ."La escritura del novelista”, 2."Las vueltas del personaje, las vueltas del narrador", 3.“Narrar el diálogo” y 4.“"El mismo lugar: novela, epifanía, negación". El primer capítulo desarrolla la tesis, mientras que el último funciona como una profundización de lo ya dicho, a manera de conclusión. Nicolás Lucero indaga de manera original en la obra del escritor argentino, ya que el asumido 
anacronismo teórico batjiniano da lugar a una reformulación lograda de la concepción tanto del personaje como del narrador y del lector en la obra de Saer.

Para Saer, la novela es un género históricamente agotado; de ahí la voluntad de fundar un proyecto de escritura coherente, replanteándose la narración bajo la forma de un problema. Lucero empieza su análisis subrayando dicho interrogante: propone ver la forma de la narrativa saeriana como un modo de pensar dialéctico, una "creatividad autocrítica" (9), apoyándose en un panorama general de la crítica saeriana. De paso, la comparación que establece con el estudio adorniano de la obra de Beethoven ${ }^{2}$ invita a pensar la prosa saeriana en términos de musicalidad. O sea que la escritura de Saer se define a través de una praxis y de la confrontación con la negatividad en un autocuestionamiento permanente, "a partir de reparos pero también de hallazgos que provienen de una consideración exhaustiva de los desafíos que plantea el arte de escribir novelas" (11). Los análisis macrotextuales de Lucero destacan la estructura de cada narración y su sentido en el conjunto del contrapunto que forman dentro de la obra; asimismo, exponen cómo los esfuerzos siempre renovados y renovadores de una búsqueda formal constituyen la seña de la voluntad saeriana de "formalizar algo nuevo que pueda traer consigo, finalmente, un sentido" (Concepto de ficción, 140). Es de notar que el "pensamiento novelístico" (11) es una manera de abarcar la literatura por el prisma del ensayo y de reformular la autotextualidad saeriana.

5 Lucero examina las claves topológicas de la zona saeriana gracias a la noción de exotopía , que Bajtín observaba en Dostoievski: "el autor ya no explica ni expone la realidad del héroe, sino que presenta su autoconsciencia como una realidad de segundo orden" (103). A su entender, Saer profundiza esta idea a través de un distanciamiento del narrador para con el personaje, pero también por medio de una estética del despojamiento y de lo que la crítica saeriana suele llamar la "moral del fracaso". Este fenómeno, en el libro de Lucero, tiene tres corolarios: la problematización del personaje en tanto que método para reconfigurar la narración, la posición del narrador como semiciego y el diálogo como indagación de la negatividad.

En "Las vueltas del personaje, las vueltas del narrador", Lucero empieza por subrayar que el método de escritura de Juan José Saer es la vuelta: vuelta de los motivos, carácter poético de su prosa, vuelta de los personajes. En efecto, los personajes más importantes suelen volver a la "zona" y de hecho, la vuelta de Europa estructura muchos relatos: en El entenado, el protagonista vuelve después de su estadía entre los indios; el narrador del ensayo El río sin orillas; Pichón Garay en La pesquisa; el Matématico en Glosa, y Gutiérrez en la La grande. Esta vuelta constante se constituye como la "matriz de toda la geometría narrativa" de Saer (23). Más allá, ciertos personajes narradores participan de la zona, no solamente por su recurrencia, sino por sus pensamientos y sus variadas relaciones con la literatura como ámbito de una praxis (lectura, traducción, periodismo, escritura). La puesta en abismo de la figura de autor-personaje permite introducir sutilmente una reflexión metatextual que domina en La vuelta incompleta: la "persistencia de (las) meditaciones" (103) de los personajes son un eco a la persistencia del "pensamiento novelístico" del autor.

7 A partir de una reflexión sobre el juego en Responso y Cicatrices basada en los personajes de Fiore, Barrios y de Sergio Escalante, Lucero subraya cómo la reintroducción del sujeto en la literatura supone, en la obra de Saer, una reformulación de la relación del sujeto con la Historia. En efecto, Saer se apropia de la epifanía joyceana, pero como revelación negativa -que se puede ejemplificar con el personaje de Barrios que ilustra la 
visión de la Historia como "casa de la coincidencia" (Glosa)-. Entonces la epifanía, que es sobre todo confrontación del personaje con lo real, adquiere en la escritura de Saer "un valor de crítica de las pretensiones de la relación entre sujeto e historia", (117). Las reflexiones sobre la causalidad y el pasado son vinculadas a cavilaciones, dudas, a cierta crisis del sentido, a un cuestionamiento del acontecimiento y a la memoria involuntaria del sujeto. El desarrollo de personaje como categoría no convencional -en el sentido del relato tradicional- da lugar a experimentaciones y sobre todo a un método. Asimismo, en "el protagonista como método" Lucero apuesta por la problematización de la relación de los personajes con la escritura como uno de los métodos de indagación fundamentales en la obra saeriana. Vuelve a justificar el vínculo estrecho del discurso crítico con el manejo de los personajes, pero desde otra perspectiva, a fin de mostrar que el gesto se sostiene por la intención de "sacar la narrativa del dominio absoluto de la épica" (Razones, 21), insertando la obra en una fértil tradición cervantina y en la denominada "moral del fracaso".

8 Lucero se detiene en un análisis profundizado de la estructura y del manejo del narrador en primera persona en Cicatrices, a fin de enfocarse en sus características formales y en el incesante juego con el horizonte de espera del lector. Emprende su reflexión a partir del cuento "Sombras sobre vidrio esmerilado", incluido en Unidad de lugar (1966), en el cual el lector accede a los pensamientos y recuerdos de la poetisa Adelina Flores en focalización interna. El relato se construye de tal manera que el lector puede asistir también a la composición de un poema por parte de la narradora, y Lucero califica esta escenificación de la escritura mental de "ejecución virtuosa" (101). Después, subraya el paso a un grado mayor de complejidad en el manejo de las focalizaciones y de los narradores en Cicatrices. En efecto, la peculiar construcción de la novela yace en su estructura: cuatro relatos que tienen poco en común y cuyo "centro cabal" es el suicidio de un personaje, Fiore. No se pueden evidenciar zonas de contacto obvias entre las tres primeras partes, pero la última aparece como contaminada por las tres precedentes porque los discursos de los personajes se pueden relacionar cada vez más con los discursos anteriores. La historia de Fiore es el punto cero de la narración y las narraciones confluyen hacia éste. Pero esta historia siempre se muestra como pura exterioridad: la novela se estructura entonces hacia un personaje exterior, a punto de suicidarse -o sea literalmente a punto de salir del elenco de la narración-. "Los cuatro relatos de la novela se orientan hacia el punto máxima exterioridad, donde se pone en evidencia que los fragmentos no se pueden juntar" (123). El centro es una disyunción que queda fuera del marco, y las intersecciones entre las órbitas de los cuatro relatos provocan cierto extrañamiento en el lector. Este paso por el análisis descriptivo es necesario para el desarrollo de un pensamiento más global en cuanto a la escritura saeriana.

$9 \quad$ Este análisis estructural y formal de Cicatrices da paso a una idea conceptual fuerte: la obra de Saer no se puede concebir como un círculo, sino como una esfera. A partir de las reflexiones de Georges Poulet ${ }^{3}$ en cuanto a la comedia humana de Balzac, Lucero señala que a diferencia de la obra balzaciana (circular), la creación saeriana puede considerarse como una esfera ya que "Cada círculo que la novela agrega (y cada círculo dentro de ese círculo) fragmenta el espacio narrativo en lugar de expandirlo y completarlo" (124). A fin de desarrollar este punto, Lucero evidencia cómo la búsqueda de Saer evoluciona en el pasaje de Cicatrices a El Limonero real, subrayando la intensificación de la frontera entre narrador y personajes, sobre todo en el dístico que aparece nueve veces a lo largo de la novela: "Amanece/ y ya está con los ojos abiertos". 
El ejercicio de close reading da paso a un examen minucioso de las articulaciones de las novelas entre sí, y de la dinámica de la obra en su conjunto.

En "un círculo de miradas semienceguecidas", Lucero desemboca en un balance de las experimentaciones de los años setenta y ochenta. El periodo de intensificación de búsqueda experimental saeriana (El limonero real, La mayor, Nadie nada nunca, Glosa) desarrolla y condensa la construcción del personaje como "punto móvil de observación" (136). Aquí, el crítico convoca a Mijaíl Bajtín ${ }^{4}$ y reformula su idea proponiendo que la creación del personaje supone no solamente cuestionar la frontera entre autor y héroe, sino que además "conjunta e inseparable, solicita la invención del narrador" (135). Entonces, el "excedente de visión" batjiniano se convierte en Saer en un "excedente de ceguera" del narrador, a través de los cambios de focalizaciones, de narradores y del campo léxico de la miopía, de lo borrado, de las incertidumbres. Es curioso aquí ver que la evocación de las metáforas vinculadas al narrador semiciego son la ocasión de un retroceso hacia la obra de juventud como fuente de metáforas para la obra venidera en la búsqueda de la "antropología especulativa" saeriana (El concepto de ficción).

11 Para ilustrar su propuesta en cuanto a la negatividad saeriana, en el capítulo "Narrar el diálogo" el crítico alude al diálogo como herramienta privilegiada de Saer en su juego narrativo. Como advertía el escritor, en su obra el diálogo permite enmarcar el relato, contrariamente al papel que se le asignaba en la narrativa hasta los años 60. Por lo cual los diálogos funcionan como un principio de articulación de la obra. "Narrar el diálogo no se restringe a un problema de técnica ni de innovación en los procedimientos, sino que tiende a confundirse con una búsqueda y una elaboración que recorren su obra entera, y que están íntimamente ligadas a la forma singular que adquiere cada uno de sus textos." (185). En Saer a menudo el diálogo lleva a una reflexión metatextual, filosófica o poética. Por eso, Lucero designa el estilo de Saer como una "poética del habla" con una incursión comparatista entre el personaje de Joe en Light in August de Faulkner y de Fiore de Cicatrices. El estilo saeriano estriba en su carácter irónico, mordaz, sarcástico, visto como una modalidad de la negatividad y de una reflexión crítica rigurosa sobre el lenguaje.

12 En última instancia, el crítico diseca una y otra vez ejemplos cuidadosamente elegidos por su aspecto polifacético, mimetizándose de cierto modo con las incesantes vueltas del mismo escritor. Así, varias nociones se repiten, se retoman, se vuelven a examinar diferentemente, en otros niveles de lectura y a través de un dispositivo que no siempre discute con la crítica. La vuelta incompleta opera entablando una relectura dinámica de la obra saeriana de cara a su producción ensayística, subsumida bajo la concepción adorniana de lo negativo como fuente dinámica de la escritura. Por ende, condensa la figura de Saer visto como un "modernista tardío" (264) por su "estética del despojamiento" y sobre todo por su "negatividad intransigente", que fundan una obra en espera de un lector crítico y atento. En su introducción, Lucero subraya que la fórmula "habría que ver" vuelve una y otra vez en boca de los personajes saerianos, y que esta concentra la estética de Juan José Saer. "Como venía diciendo" (íncipit de Lo imborrable) resuena como un eco que condensaría el recorrido de Nicolás Lucero. 


\section{NOTAS}

1. El libro es el fruto de una tesis emprendida bajo la dirección de Daniel Balderston y defendida en el 2006.

2. Adorno, Theodor, Beethoven, The Philosophy of Music. Fragments and Texts edited by Rolf Tiedmann. Traducción de Edmund Jephcott. Stanford: Stanford University Press, 1998.

3. Poulet, Georges, The Matamorphoses of the Circle. Trad. Carley Dawson y Elliott Coleman en colaboración con el autor. Baltimore: The Johns Hopkins Press, 1966.

4. Bajtín, Mijaíl, “Autor y héroe en la actividad estética”, Estética de la creación verbal. México: Siglo XXI, 1989, p.13-190.

\section{AUTORES}

\section{PERRINE GUÉGUEN}

Université Paris 8 Vincennes-Saint-Denis

pgueguen1987@gmail.com 